\title{
SUPERSONIC, TURBULENT FLOW COMPUTATION AND DRAG OPTIMIZATION FOR AXISYMMETRIC AFTERBODIES
}

\author{
R. M. CUMMINGS, ${ }^{\prime}$ H. T. YANG ${ }^{1}$ and Y. H. $\mathrm{OH}^{2}$ \\ 'Department of Aerospace Engineering, University of Southern California, Los Angeles, \\ California, U.S.A. \\ ${ }^{2}$ Hughes Aircraft Company, Canoga Park, California, U.S.A.
}

\begin{abstract}
The compressible, turbulent flow about an axisymmetric body was numerically studied using the MacCormack unsplit explicit algorithm applied to the mass-average Navier-Stokes equations solved in conjunction with the $k-\epsilon$ turbulence model of Jones and Launder. Numerical predictions of total body drag (pressure drag, skin friction drag. and base drag) were made for an axisymmetric body six diameters in length, with and without a boattail. Surface pressures and viscous layer profiles are compared with available wind tunnel data and are found to be in good agreement for both geometries. The Golden Section optimization method was used to optimize the body boattail angle for minimum drag. The solution method can serve as a tool for preliminary design analysis where the relative merits of utilizing boattails on axisymmetric afterbodies is being considered.
\end{abstract}

\section{INTRODUCTION}

As supersonic aircraft and missiles reach higher velocities and require greater performance, the procedures used for their design must be evaluated. New performance requirements often dictate new designs, and previous methods of analyzing aerodynamics may need improving.

A major constraint on the performance of an aerodynamic body is drag. A supersonic body will have major drag contributions from pressure drag, skin friction drag, and base drag. Obtaining valid predictions for these drag components, and thus having valid tools for design purposes, is difficult at best. Specifically, the prediction of base drag in an accurate manner has long eluded the practicing engineer.

Some of the difficulties in the prediction of base drag have included: (1) the upstream effects of the presence of a corner in various Mach number flows at different Reynolds numbers, (2) the effects of separation, compression and/or expansion, and shock formation in the vicinity of the corner, (3) the structure of the recirculating zone, (4) the formation and structure of a mixing (shear) layer between the recirculating zone and the external flow, and (5) the effects of the configuration (e.g., boattails, fins, etc.).

These complexities and the difficulties associated with accurately predicting the flow processes have led researchers to utilize various semi-empirical prediction methods which were valuable but very limited in their application [1]. The recent advances in computational capabilities, namely increased computer memory size and processing speed, as wcll as improved numcrical methods, have enabled attempts at solving the Navier-Stokes equations for the flow around a base. Early predictions were limited in size and scope by the solution algorithm method and by the capabilities of the computer, but eventually practical solutions were obtained. Table 1 presents a summary of recent numerical studies of the flow over backward-facing steps and axisymmetric boattailed bodies, with and without jet plumes [2-17]. Many of these works were necessarily limited in scope by computational restrictions. Some researchers included the effects of the forebody by using inviscid computations in conjunction with solutions of the viscous fluid flow equations in a zonal approach (the inviscid solutions were used to provide the inflow boundary conditions for the base 
Table 1. Survey of base flow computations

\begin{tabular}{lccl}
\hline \multicolumn{1}{c}{ Researcher } & Geometry $\dagger$ & Model $t$ & Remarks \\
\hline Deiwert [2] & 3D & 1 & Thin shear-layer \\
Deiwert [3] & 2D & 1 & Thin shear-layer with jet \\
Deiwert and Rothmund [4] & 3D & 1 & Thin shear-layer with jet \\
Gosman et al. [5] & 2D & 2 & \\
Hah and Lakshiminaryana [6] & 3D & 2,3 & Curvature effects \\
Holst [7] & 2D & 1 & With jet \\
Hutton and Smith [8] & 2D & 2 & \\
Mansour et al. [9] & 2D & 2 & With jet \\
Mikhail et al. [10] & 2D & 1 & \\
Oh and Harris [1]] & 3D & 1 & \\
Pope and Whitelaw [12] & 2D & 2,3 & \\
Rhie and Chow [13] & 2D & 2 & Thin shear-layer \\
Sahu et al. [14] & 2D & 1 & Thin shear-layer with jet \\
Sahu et al. [15] & 2D & 1 & \\
Sturek et al. [16] & 3D & 1 & \\
Vanka [17] & 2D & 2 & \\
Weinberg et al. [18] & 2D & 3 &
\end{tabular}

Notc: $2 \mathrm{D}$ includes both two dimensional and axisymmetric.

$\$$ Types of turbulence models.

1 = Algebraic eddy-viscosity, 2 = differential eddy-viscosity, 3 = Reynolds stress.

region). Only recently have computations been made for the entire flowfield about an axisymmetric body using the average Navier-Stokes equations in conjunction with a turbulence model capable of predicting the recirculating flow found in the base region.

A logical next step in this evolution is to begin using these computations as a practical preliminary design tool, especially as a method for optimizing geometries for minimizing drag. The goal of this research is to numerically solve the Navier-Stokes equations for compressible, turbulent flow as applied to an axisymmetric body with a boattailed base. The boattail angle is then optimized to determine the geometry for minimum total drag (including pressure drag, skin friction drag, and base drag). As these types of applications are improved and extended, the modern designer will have a valuable tool to go along with wind tunnel testing as new configurations are explored for use on aircraft.

\section{NAVIER-STOKES EQUATIONS FOR COMPRESSIBLE FLOW}

Many researchers have applied various simplified sets of fluid dynamics equations to model the flow around axisymmetric bodies. However, due to the complexity of the fluid flow in the base region of an axisymmetric body, the Navier-Stokes equations with an appropriate turbulence model are required to accurately describe the fluid motion. Base flow is inherently turbulent and accurate results require a detailed description of various turbulence quantities. But current computer memory storage size and computational speeds prohibit analyzing turbulence at its fundamental scales for full-scale configurations. At present, even the largest computers can only simulate turbulence for simple flows with highly constrained flow parameters [19], and methods utilizing chaos theory were developed to enhance understanding of the fundamental processes of turbulence [20]. Due to these restraints, the full Navier-Stokes equations must be used in averaged form with some type of semi-empirical turbulence model to effect closure of the set of equations.

\subsection{Mass-averaged equations}

The intricate equations which result from Reynolds-averaging the compressible flow equations can be avoided through the use of mass-weighted variables. Hesselberg [21] first used mass-weighted variables for atmospheric studies, and later Favre $[22,23]$ generalized their use for the equations of compressible fluid motion. Mass-weighting is accomplished by decomposing the variables as

$$
A=\tilde{A}+A^{\prime \prime}
$$

where

$$
\tilde{A} \text {-mass-weighted quantity } \equiv \frac{\overline{\rho A}}{\bar{\rho}}
$$

$A^{\prime \prime}$-fluctuating quantity 
and

$$
\overline{\rho A^{\prime \prime}}=0
$$

The mass-weighted average is chosen so that the average flux of mass across a streamline vanishes if mass is conserved. This is accomplished by taking the mass-weighted average of velocity, total energy, and temperature, while taking the Reynolds-average of density, pressure, and viscosity.

\subsection{Turbulence closure}

Most numerical investigations of base flows either use algebraic or differential 'eddy-viscosity' turbulence models to attain turbulence closure (see Table 1). Although some investigators have utilized stress transport models for recirculating flow, Pope and Whitelaw [12] showed that the added expense in computation time for solving the multi-equation models was not justified if only mean-flow properties were being considered. And while algebraic models provide a computationally inexpensive method for calculating base flows, they do not possess the ability to accurately calculate recirculating flow $[24,25]$.

Several two-equation modes exist and usually include one equation to model the turbulent kinetic energy, $\tilde{k}$, and another equation to model turbulent dissipation, mixing length, or some combination of the two. Several investigators have compared the relative abilities of the various two-equation models to predict base flow $[18,26]$. Most of the comparisons show only small differences in predictive capabilities among the models, with the $k-c$ model being shown to have the best overall applicability. Therefore, closure of the equations of motion will be attained through the use of the $k-t$ turbulence model $[27,28]$ and the notion of turbulent eddy-viscosity.

The $k-\epsilon$ turbulence model was developed for an incompressible fluid and has been shown to be very good for representing flows of a complex nature (such as recirculating flows). Morkovin [29] has hypothesized that the basic turbulence mechanisms which are found in incompressible flows are identical in nature to those found in compressible flow. Morkovin based his hypothesis on the concept that the maximum turbulent velocity fluctuations were approx. $20 \%$ of the mean velocity. Therefore, the velocity fluctuations would be subsonic as long as the freestream Mach number was below five. Rubesin [30] has shown that the use of the $k-c$ turbulence model developed by Jones and Launder and interpreted with mass-weighted variables in compressible flow leads to a turbulence representation which is generally accurate for flowfields at Mach numbers below five. Liakopoulos [31] showed that the $k-c$ model was highly accurate in predicting viscous layer turbulence quantities in compressible flow.

The turbulence viscosity relation for the $k-\epsilon$ turbulence model is

$$
\mu_{\mathrm{t}}=c_{\mu} \bar{\rho} \frac{\tilde{k}^{2}}{c}
$$

The turbulent kinetic energy, $\tilde{k}$, and the turbulence dissipation rate, $\epsilon$, are represented by modeled differential equations in Ref. [27]. The values used for the empirical constants in incompressible flow closure are from the original Jones and Launder model $[27,32]$ as well as a model modified for recirculating flows by Hutton and Smith [8]. Both models were utilized for comparison with measured data (results are shown in Section 5).

The turbulence closure equations are also modified in order to simplify the numerical boundary conditions by allowing the turbulent dissipation to go to zero at the wall $[27,32]$. The numerical constants are modified by the turbulence Reynolds number,

$$
R_{\mathbf{T}}=\frac{\bar{\rho} \tilde{k}^{2}}{\bar{\mu} \epsilon}
$$

which allows the turbulence model to give reasonable results for small values of $R_{\mathrm{T}}$ near a solid, stationary surface.

The Reynolds stress and temperature fluctuations are modeled after the turbulent mixing coefficient introduced by Boussinesq [33]. The use of this coefficient assumes that the turbulent viscosity, $\mu_{t}$, can be based on the concept of Stoke's Law for laminar flow. The eddy-viscosity relationship for the $k-c$ turbulence model is [33]

$$
\overline{-\rho u_{i}^{\prime \prime} u_{j}^{\prime \prime}}=-\delta_{i j} \frac{2}{\rho} \bar{\rho} \tilde{k}+2 \mu_{\mathrm{t}} \tilde{S}_{i j}
$$


where

$$
\tilde{S}_{i, j}=\frac{1}{2}\left(\tilde{u}_{i, j}+\tilde{u}_{j, i}\right)-\frac{1}{3} \delta_{i j} \tilde{u}_{k, k}
$$

This relationship differs from its incompressible counterpart in that the mean rate-of-strain tensor is modified by the mean divergence, which is not zero in compressible flow. The laminar viscosity, $\bar{\mu}$, is computed using Sutherland's formula.

\subsection{Equations of fluid motion}

When the compressible Navier-Stokes equations and the $k-\epsilon$ turbulence model are written for axisymmetric flow and vectorized, they take the form

$$
\frac{\partial Q}{\partial t}+\frac{\partial E}{\partial r}+\frac{\partial F}{\partial z}+H=0
$$

where the vectors are given by

$$
\begin{aligned}
& Q=r\left[\begin{array}{c}
\bar{\rho} \\
\bar{\rho} \tilde{u}_{r} \\
\bar{\rho} \tilde{u}_{2} \\
\bar{\rho} \tilde{E} \\
\bar{\rho} \hat{k} \\
\bar{\rho} \epsilon
\end{array}\right] \\
& E=r\left[\begin{array}{c}
\bar{\rho} \tilde{u}_{r} \\
\bar{\rho} \tilde{u}_{r} \tilde{u}_{r}+\bar{p}-\overline{\tau_{r r}} \\
\bar{\rho} \tilde{u}_{z} \tilde{u}_{r}-\overline{\tau_{z r}}-\overline{u_{r}}(\bar{\rho} \tilde{E}+\bar{p})+\bar{q}_{r}-\tilde{u}_{r} \bar{\tau}_{r r}-\tilde{u}_{r} \overline{\tau_{z r}} \\
\bar{\rho} \tilde{u}_{r} \tilde{k}-\left(\bar{\mu}+\frac{\mu_{t}}{\sigma_{k}}\right) \frac{\partial \tilde{k}}{\partial r} \\
\bar{\rho} \tilde{u}_{r} \epsilon-\left(\bar{\mu}+\frac{\mu_{1}}{\sigma_{k}}\right) \frac{\partial \epsilon}{\partial r}
\end{array}\right] \\
& F=r\left[\begin{array}{c}
\bar{\rho} \tilde{u}_{z} \\
\bar{\rho} \tilde{u}_{r} \tilde{u}_{z}+\bar{p}-\overline{\tau_{r z}} \\
\bar{\rho} \tilde{u}_{z} \tilde{u}_{z}-\overline{\tau_{z z}} \\
\tilde{u}_{z}(\bar{\rho} \tilde{E}+\bar{p})+\overline{q_{z}}-\tilde{u}_{r} \overline{\tau_{r z}}-\tilde{u}_{z} \overline{\tau_{z z}} \\
\bar{\rho} \tilde{u}_{z} \tilde{k}-\left(\bar{\mu}+\frac{\mu_{\mathrm{t}}}{\sigma_{k}}\right) \frac{\partial \tilde{k}}{\partial z} \\
\bar{\rho} \tilde{u}_{z} \epsilon-\left(\bar{\mu}+\begin{array}{c}
\mu_{\mathrm{t}} \\
\sigma_{k}
\end{array}\right) \frac{\partial \epsilon}{\partial z}
\end{array}\right] \\
& H=\left[\begin{array}{c}
0 \\
-\bar{p}+\overline{\tau_{\theta \theta}} \\
0 \\
0 \\
r(P-\bar{\rho} \epsilon) \\
r \epsilon\left(C_{1} P-C_{2} \bar{\rho} \epsilon\right)
\end{array}\right] \\
& \bar{p}=\bar{\rho} R \tilde{T}
\end{aligned}
$$


where the shear stress terms, the heat flux terms, the turbulence production term, and the constants are defined in Ref. [34]. These equations, together with the $k-\epsilon$ turbulence model, are equivalent to the compressible Navier-Stokes equations with mass-weighted variables developed by Rubesin and Rose [35] who used enthalpy rather than temperature for the energy equation.

\section{NUMERICAL FORMULATION}

The mass-averaged Navier-Stokes equations for axisymmetric, compressible flow, including the turbulence model, are given by six coupled, non-linear partial differential equations. These equations do not have a general closed-form analytic solution due to a lack of knowledge of the solution of non-linear partial differential equations. Consequently, researchers employ various numerical schemes to obtain solutions for specific problems. The unsteady compressible Navier-Stokes equations are a set of hyperbolic/parabolic partial differential equations which require the use of specialized numerical algorithms for their solution. A finite difference algorithm will be considered due to the proven capability of these algorithms in solving the unsteady compressible Navier-Stokes equations.

\subsection{MacCormack's unsplit explicit algorithm}

Applying the unsplit explicit MacCormack scheme [36] to these vectorized equations [equations $(7-11)]$ results in the following two-step algorithm

Predictor step:

$$
\overline{Q_{i, j}^{n+1}}=Q_{i, j}^{n}-\frac{\Delta t}{\Delta r}\left(E_{i, j+1}^{n}-E_{i, j}^{n}\right)-\frac{\Delta t}{\Delta z}\left(F_{i+1, j}^{n}-F_{i, j}^{n}\right)-\Delta t H_{i, j}^{n}
$$

Corrector step:

$$
Q_{i, j}^{n+1}==\frac{1}{2}\left[Q_{i, j}^{n}+\overline{Q_{i, j}^{n+1}}-\frac{\Delta t}{\Delta r}\left(\overline{E_{i, j}^{n+1}}-\overline{E_{i, j-1}^{n+1}}\right)-\frac{\Delta t}{\Delta z}\left(\overline{F_{i, j}^{n+1}}-\overline{F_{i-1, j}^{n+1}}\right)-\Delta t \overline{H_{i, j}^{n+1}}\right]
$$

where quantities with an overbar represent predicted values. This explicit scheme is second-order accurate in space and time. Forward differences are used in the predictor step and backward differences are used in the corrector step.

Several derivatives appear in the viscous terms of $E, F$, and $H$, and care must be taken in their differencing in order to maintain second-order accuracy. The $r$-derivatives in $E$ are differenced in the opposite direction of the predictor step, while the $z$-derivatives are central-differenced. Likewise, the $z$-derivatives in $F$ are differenced in the opposite direction of the predictor step, while the $r$-derivatives are central-differenced [37]. All viscous terms are calculated only in the predictor step using second-order accurate central differencing in order to reduce the computation time. The resulting viscous terms are then applied to both the predictor and corrector steps, resulting in first-order time axcuracy.

\subsection{Time step calculation}

Explicit algorithms require a restriction on the time step in order to insure stability. This time step restriction is the reason explicit methods require greater computational work to progress a finite amount of time than implicit methods. Due to the complexity of the equation set, no stability analysis for the MacCormack scheme applied to the compressible Navier-Stokes equations is available. However, Tannehill et al. [38] empirically modified the CFL stability condition, and this approach is used in the present computations. The time step is calculated at each grid point and the smallest $\Delta t$ in the computational region is used to advance the solution.

\subsection{Artificial smoothing}

When using finite difference algorithms to capture shocks in compressible flow, a non-linear instability is encountered in the vicinity of the shock [39]. The instability is caused by the large gradients in the fow variables which exist across a shock. These large gradients create oscillations in the numerical treatment due to truncation error. In the case of the Navier-Stokes equations, this oscillation could be reduced by utilizing an extremely fine mesh, which is usually impractical for most applications. 
The non-linear instability is overcome by adding an artificial damping term to the equations of fluid motion which will "smooth" the shock gradient over a number of grid points. The damping term is usually of fourth-order so that it will only be added where large gradients exist, the majority of the flowfield being relatively unaffected by the smoothing term.

The artificial damping term used in this work was developed by Holst [7] as a modification to the "product" fourth-order smoothing used by Tannehill et al. [38]. The damping is equivalent to adding an artificial viscosity of the form

$$
c_{z} \frac{\Delta z^{4}}{4 \bar{p}} \frac{\partial^{2} \bar{p}}{\partial z^{2}} \frac{\partial^{2} Q}{\partial z^{2}}
$$

to the finite-difference equations, where $c_{z}$ is a constant, which must be less than or equal to 0.5 to maintain stability [7].

\subsection{Computational plane and grid generation}

The physical plane grid is transformed to the uniform computational grid by applying a spatial transformation followed by a grid clustering. The grids were calculated using an error function algebraic stretching scheme developed by $\mathrm{Oh}[40,41]$. The details of the transformation and grid clustering are presented in Ref. [34]. A grid resolution study was performed and is reported in a later section.

\subsection{Boundary conditions}

The boundary conditions required for the numerical treatment of compressible, turbulent flow over an axisymmetric body can be divided into five types (see Fig. 1): inflow, outflow, upper inflow/outflow, centerline, and wall.

Since the inflow will be entirely supersonic, the inflow variables may be prescribed to represent a uniform freestream flow, i.e., $\bar{\rho}, \tilde{u}_{r}, \tilde{u}_{r}$, and $\tilde{T}$ are prescribed, while $\bar{p}$ and $\tilde{E}$ are calculated using the Perfect Gas Law and the definition of total energy.

The outflow boundary will be prescribed far enough downstream from the body (approx. 20 body diameters downstream from the base) for the entire plane to have recovered to supersonic conditions; therefore, the outflow variables will be extrapolated. This method has been found to work well with supersonic flow and has a good physical basis [39]. $\bar{\rho}, \tilde{u}_{z}, \tilde{u}_{r}$, and $\tilde{E}$ are linearly extrapolated using the flux terms, $Q$, which is defined in equation (8). $\hat{T}$ and $\bar{p}$ are calculated using the Perfect Gas Law and the definition of total energy.

The upper boundary is assumed to be an inflow/outflow surface which may be treated with a simple characteristic solution [39]. Physically, this boundary condition is approximated as an inviscid boundary, which is justified if the boundary is far removed from any viscous regions, and the viscous terms are deactivated near the boundary.

Care must be taken in defining the boundary condition for the flow centerline. The use of cylindrical coordinates creates a difficult condition since $r=0$ at the centerline, and certain terms

UPPER INFLOW/OUTFLOW

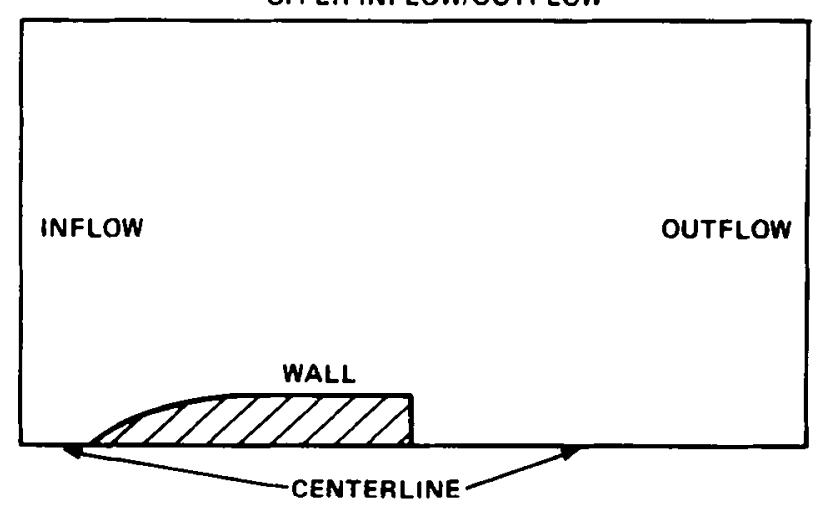

Fig. 1. Physical plane boundaries. 
in the governing equations require special attention [39]. The correct boundary conditions at the flow centerline are

$$
\frac{\partial}{\partial r}\left(\tilde{u}_{z}, \bar{\rho}, \bar{p}, \tilde{E}\right)=\tilde{u}_{r}=0
$$

As an example of how to handle the centerline conditions, consider the mass conservation equation, and divide by $r$ to yield

$$
\frac{\partial}{\partial t}(\bar{\rho})+\frac{\partial}{\partial z}\left(\bar{\rho} \bar{u}_{z}\right)+\frac{1}{r} \frac{\partial}{\partial r}\left(r \bar{\rho} \tilde{u}_{r}\right)=0
$$

Applying the chain rule to the last term in equation (16) yields

$$
\frac{1}{r} \frac{\partial}{\partial r}\left(r \bar{\rho} \tilde{u}_{r}\right)=\frac{\partial}{\partial r}\left(\bar{\rho} \tilde{u}_{r}\right)+\frac{\bar{\rho} \tilde{u}_{r}}{r}
$$

and using L'Hopital's rule, the last term in equation (17) may also be reevaluated to yield a mass conservation equation valid at $r=0$

$$
\frac{\partial}{\partial t}(\bar{\rho})+\frac{\partial}{\partial z}\left(\bar{\rho} \tilde{u}_{z}\right)+2 \frac{\partial}{\partial r}\left(\bar{\rho} \tilde{u}_{r}\right)=0
$$

This operation may be performed on all of the radial derivative terms in the mass, momentum, energy, and turbulence equations. The $\partial / \partial r$ derivatives are taken using a one-sided, second-order accurate formula, with appropriate reflection values.

The boundary conditions on the wall are relatively straightforward, with the exception of the boundary conditions at the sharp corner at the base. The boundary conditions along the wall reflect that the fluid does not slip along the surface, i.e., $\tilde{u}_{z}=\tilde{u}_{r}=0$. The wall surface is assumed to be adiabatic so that the boundary condition for temperature is given by $\tilde{T}_{\text {wall }}=\tilde{T}_{i, j+1}$. This is justified for approximating wind tunnel conditions where the model reaches an equilibrium temperature after the tunnel has been operating for a short period of time. The final wall boundary condition required is a condition for either the pressure or the density. An approach which has been found to work well for high Reynolds number viscous flows is to assume that the pressure gradient at the wall is invariant [42], $\partial p / \partial n=0$. This provides the necessary wall boundary conditions, along with the equation of state to provide the resulting value of the density.

The sharp corner at the base requires special attention in order to avoid inappropriate flow variable values being used in the numerical differencing. For example, when calculating fluid quantities at the grid point directly above the sharp corner, values of pressure, density, and temperature may be required at the wall. These values should correspond to the flow along the body, not the flow at the base. Similarly, when differencing is being done at the grid point immediately behind the sharp corner, the values of pressure, density, and temperature must correspond to the base flow.

In order to insure that the correct values of pressure, density, and temperature are used in the vicinity of the sharp corner, dual values of these flow variables are retained and used accordingly. This treatment allows for the various flow regions (wall viscous layer or base) to "feel" different fuid properties at the sharp corner.

The turbulence quantities, $\tilde{k}$ and $\epsilon$, are set to very small values at the outer edge of the flow as is appropriate for freestream conditions. The value of $\tilde{k}$ is set equal to zero at the wall, which corresponds to the fact that the velocity fluctuations must vanish at a solid surface. The value of $\epsilon$ is set equal to zero at the wall by adding terms to the differential equations governing the turbulence model, which is computationally advantageous [27].

\section{OPTIMIZATION TECHNIQUE}

The goal of any mathematical optimization is to extremize (minimize or maximize) some objective function, $F$. The objective function must be expressible as a single value for the optimization technique to operate, but $F$ may be a function of several design variables, $X_{1}, X_{2}, \ldots, X_{N}$, which are free constants selected in order to minimize $F$ [43]. In principle, as many design variables, $N$, as desired may be used. However, in practice the number of design variables 


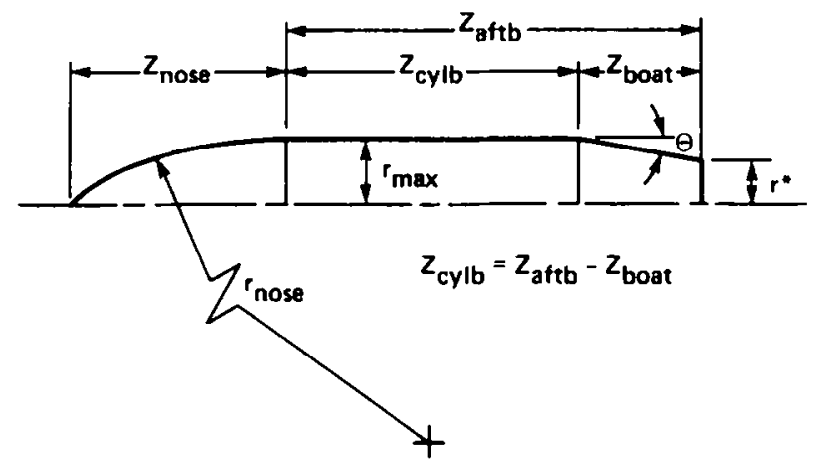

Fig. 2. Axisymmetric body geometry.

is kept at a minimum since the optimization efficiency and computational time for most algorithms varies proportionally as $N^{2}[44,45]$.

\subsection{Aspects of drag optimization}

Before choosing a minimization algorithm, the general aspects of the problem to be solved must be defined. By evaluating the various minimization techniques with the specific problem in mind, a good choice of technique can be made. The goal of this computation is to predict the total drag of an axisymmetric body at zero angle of attack in compressible turbulent flow. The drag will be determined as the sum of the pressure drag, skin friction drag, and base drag.

The only design variable which will be considered for optimization is the boattail angle, $\Theta$ (see Fig. 2). The boattail length, $z_{\text {boat }}$, will not be considered as an additional design variable since experiments have shown that body drag decreases approximately linearly with increasing boattail length [46]. An optimization of boattail length would always result in the largest constrained value of boattail length. As the boattail angle varies, the drag components due to pressure and skin friction will vary, yielding a minimum value at some boattail angle within prescribed constraints. The goal of the optimization is to obtain the body shape which minimizes drag for a given geometry type, therefore the objective function is the total drag. Since only one design variable is being used, it will be helpful to know a priori the general relationship of drag with the boattail angle.

Data from various wind tunnel investigations of boattail body shapes at supersonic speeds show a consistent variation of drag with the boattail angle (Fig. 3) [46]. Since this case represents a single dimension design space which is known to be unimodal, the search method can be chosen in order to efficiently obtain the minimum objective function, with the overall goal being to minimize total computation time (both the time of operating the search method and the time of calculating the objective function). Based on this knowlege of the design space, a reasonable search method would be an elimination technique, especially since all of the gradient methods would require analysis of $\nabla F$, a very time consuming operating (each computation of $F$ will require one converged solution of the MacCormack algorithm-minimizing the number of evaluations of $F$ is paramount to overall

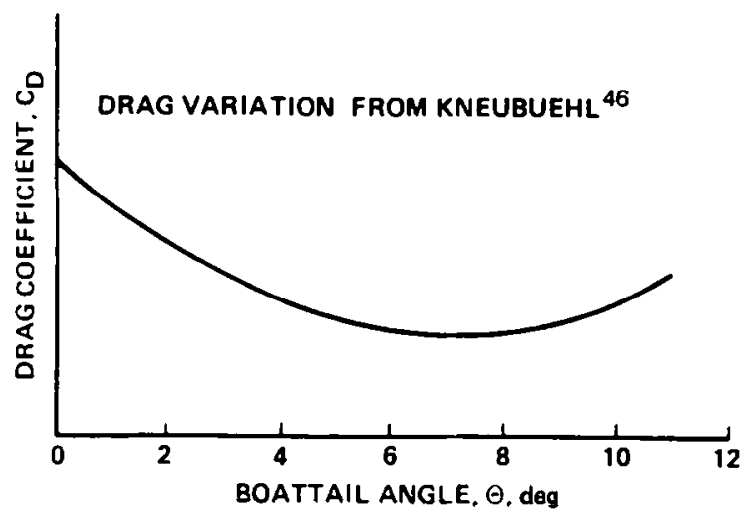

Fig. 3. Variation of drag with boattail angle. 
computational efficiency). The Golden Section method will be used for this optimization due to its robust nature and capability to locate a minimum without using derivatives.

\subsection{The Golden Section optimization method}

The Golden Section search technique [47] is a discrete search method which utilizes previously determined information about the objective function in order to reduce the design space search area. The method requires $a$ priori knowledge that the objective function is unimodal (has a single extremum) within the constrained section of the design space. The biggest advantage of the method is that it does not require the use of gradient information, which in the present case would require several evaluations of the objective function (drag) for each search step.

Consider an objective function, $F$, with one design variable, $X$, and a known minimum between two design variable constraints, $\alpha_{1}$ and $\alpha_{3}$ (see Fig. 4). Any three $\alpha$-values, $\alpha_{1}<\alpha_{2}<\alpha_{3}$, form a bracket around the $\alpha$ corresponding to $F_{\min }$ if $F_{2} \leqslant \min \left(F_{1}, F_{3}\right)$. Once this search bracket is located, the design space may be reduced by sectioning.

The ratio $\alpha_{3}-\alpha_{2}: \alpha_{2}-\alpha_{1}$, is used to calculate the ratio $\tau: 1$ (where $\tau>1$ ). An additional point, $\alpha_{4}$, is inserted in order to reduce the search bracket, and both potential new brackets, $\left(\alpha_{1}, \alpha_{2}, \alpha_{4}\right)$ or $\left(\alpha_{2}, \alpha_{4}, \alpha_{3}\right)$, are required to have intervals of the same ratio, $\tau: 1$. By symmetry, $\alpha_{3}-\alpha_{4}=\alpha_{2}-\alpha_{1}$, and the ratio $\alpha_{4}-\alpha_{2}: \alpha_{2}-\alpha_{1}$ yields that $\tau$ must satisfy $1=\tau^{2} /(\tau+1)$, i.e., that $\tau$ is the positive root of $\tau^{2}-\tau-1=0(\tau=(1+\sqrt{5}) / 2)$. The Golden Section method evaluates $F$ at the new point and determines the new reduced interval which maintains the ratio. This process is repeated until the minimum value of $F$ is found within some convergence criteria [47].

The number of iterations required to compute the minimum value of the objective function is dependent on the desired accuracy. For example, using the geometry of interest, the Golden Section method could theoretically locate the boattail angle for minimizing drag within 9 iterations for $1 \%$ accuracy, and within 5 iterations for $10 \%$ accuracy.

\section{COMPUTATIONAL RESULTS}

In order to have confidence in the results of the boattail optimization, the numerical code should be validated against available experimental data. If possible, especially when computing turbulent flow, a detailed comparison of flowfield quantities should be made. Unfortunately, very few experimental results exist for flowfield quantities in supersonic flow. This is partially due to the difficulty in measuring turbulent quantities in compressible flow, and the difficulty in truly understanding what is being measured. Once the code is validated, the numerical optimization will be run in order to determine the optimum boattail shape for minimizing overall drag. Due to the lack of data, there will be no way to exactly validate the optimized geometry flowfield characteristics. It is hoped that the validated code gives reasonable results at off-validation conditions.

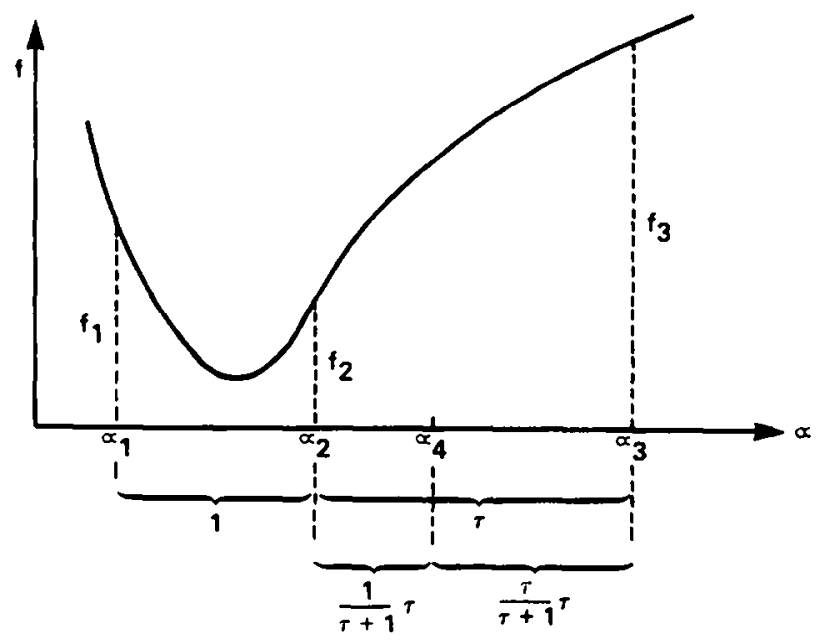

Fig. 4. The Golden Section search method. 


\subsection{Experimental data}

The Army Ballistic Research Laboratories conducted a series of wind tunnel tests which were intended to provide a wide range of experimental data for axisymmetric bodies with boattails [48-51]. These data were specifically taken for use in comparing with numerical predictions, and include many of the measurements which are useful for that purpose.

The geometry chosen for comparison is an axisymmetric body six diameters in length, with secant-ogive forebody/cylindrical afterbody, with and without a boattail. The dimensions corresponding to Fig. 2 are: $r_{\text {nose }}=18.88, z_{\text {nose }}=3.0, z_{\text {cylb }}=2.0, z_{\text {boat }}=1.0 . r^{*}=0.38$, and $r_{\max }=0.5$. These dimensions are in body diameters - the body diameter is $5.715 \mathrm{~cm}(2.25 \mathrm{in})$-and result in a $7^{\circ}$ conical boattail. Several tests were conducted to measure both surface pressures and boundary layer quantities at Mach 3.0. Additionally, surface pressures were also measured at Mach 2.0 and Mach 4.0.

The wind tunnel tests were run at a nominal Reynolds numbers of $6.5 \times 10^{6}$ (based on the body length). The pressure data were taken from 10 pressure taps made of $0.65 \mathrm{~cm}$ tubing approx. $3.0 \mathrm{~m}$ in length. Pressures were measured at axial locations along the body of $Z / D=0.89,1.56,2.22,2.79$, $3.13,3.56,4.22,4.88,5.32$, and 5.77. The turbulent boundary layer data were taken using an impact pressure probe.

\subsection{Grid resolution}

In order to properly resolve the important flowfield features, it is necessary to cluster grid points in regions of high gradients of the flowfield variables. As was stated previously, the grid clustering is accomplished using an error function algebraic stretching function which enables grid spacing to vary in both the axial and radial directions.

The particulars of the flowfield being solved must be taken into account when placing grid points; more grids are required in the shock layer, viscous layer, and baseflow region than are required in the regions far away from the body. In fact, the grid spacing near the body must be several orders of magnitude smaller than the freestream spacing in order to resolve the complexities of the viscous layer, with at least one grid point being placed within the laminar sub-layer of the viscous layer. If this were not done, then the inner portion of the viscous layer would not be properly modeled.

The grid for the body with a $7^{\circ}$ boattail is shown in Fig. 5. The grid has 121 points in the axial direction and 81 points in the radial direction, with approx. 70 axial points used to resolve the flow features of the body, and 30 radial points used to resolve the viscous layer. Additional radial points were required due to the presence of the base region, which contains approx. 20 radial points; 50 of the 81 radial grid points are contained within a region very close to the body.

The radially-spaced grid clustering near the body for the viscous layer is quite apparent, and this clustering continues downstream of the base in order to capture the important features of the shear layer in that region. Also, finer grid clustering in the axial direction is used at the base in order to more accurately predict the effects of the base on the recirculation region which forms immediately behind the base. The base region grid with a 7 boattail is shown in greater detail in Fig. 6. Finally, a small amount of grid clustering is used near the vertex of the forebody, as shown in Fig. 5. This is done in order to better resolve the high gradients which occur at the stagnation point at the nose (the stagnation point initiates the shock wave which begins at the nose). Without this clustering, grid points near the nose would be forced to difference flow variables from points in the freestream, across the shock, and into the initial viscous layer.

The grid was refined in order to strike a balance between the computational time and the accuracy of the solution; the greater the grid resolution, the longer the computation time. In order to gain confidence in the selection of the grid, three separate grids were used to predict the drag of the axisymmetric body. A coarse grid $(61 \times 41)$, medium grid $(121 \times 81)$, and fine grid $(181 \times 121)$ have been used for the prediction. The coarse grid converges to within one percent of the final solution in approx. 400 time steps, reaching a final value of $C_{\mathrm{D}}=0.375$. However, this solution is unreliable due to the coarseness of the grid in the vicinity of the body and base region. Large gradients in the flowfield variables are probably not properly resolved by this grid. The medium grid has a slower convergence rate than the coarse grid, taking approx. 700 time steps to converge to within one percent of the final solution. Notice that the final drag coefficient result 


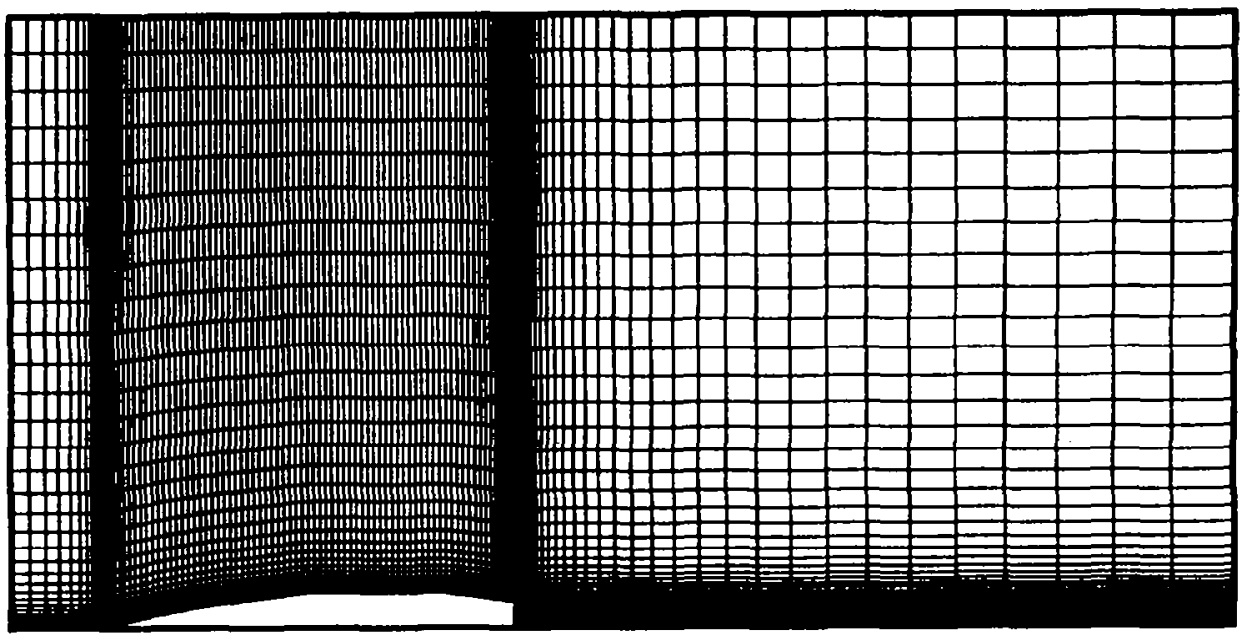

Fig. 5. Physical plane grid with $7^{\circ}$ boattail $(121 \times 81)$.

for the medium grid $\left(C_{\mathrm{D}}=0.355\right)$ is less than the result for the coarse grid by nearly 10 percent. Finally, a fine grid solution shows that the drag coefficient value of $C_{D}=0.355$ is a good solution. The fine grid has an even slower convergence rate than the medium grid, taking 1000 time steps to reach within one percent of the final solution. The medium grid yields the same qualitative results as the fine grid in less computation time, and will therefore be used for the remainder of the numerical predictions.

\subsection{Numerical/experimental considerations}

The wind tunnel model had a strip of grit $4.06 \mathrm{~cm}$ from the nose tip in order to induce transition to turbulent flow. This condition was simulated by allowing only laminar viscosity to be calculated ahead of the transition point, with the turbulent viscosity being calculated behind the transition point. The turbulent viscosity is ramped up to the predicted viscous level over a five grid axial distance. This gives better results by not allowing a step function of turbulent viscosity, and better simulates the transitional nature of the viscous layer, which occurs over a finite length.

\subsection{Numerical predictions for Mach 3.0}

The primary results for which test data are available are at a freestream Mach number of 3.0. Further validations with available experimental data were done at Mach numbers 2.0 and 4.0 before optimizing the boattail angle [34]. Data are available for boattail angles, 0 and $7^{\circ}$, with both cases being computed.

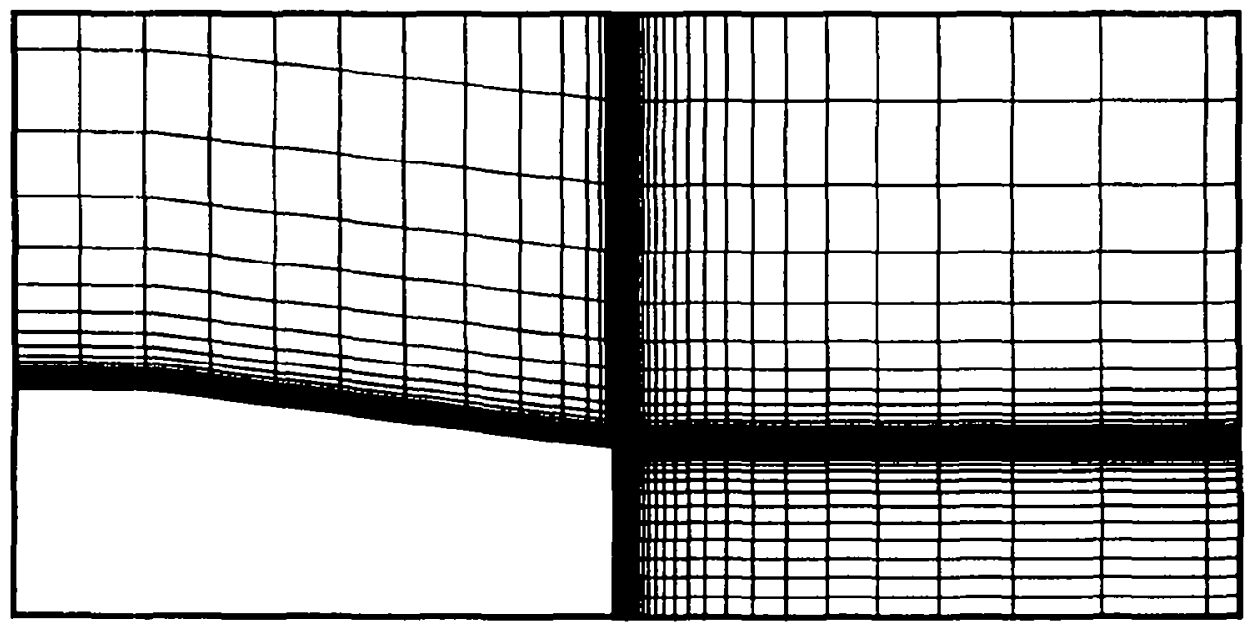

Fig. 6. Physical plane grid near base with $7^{\circ}$ boattail. 


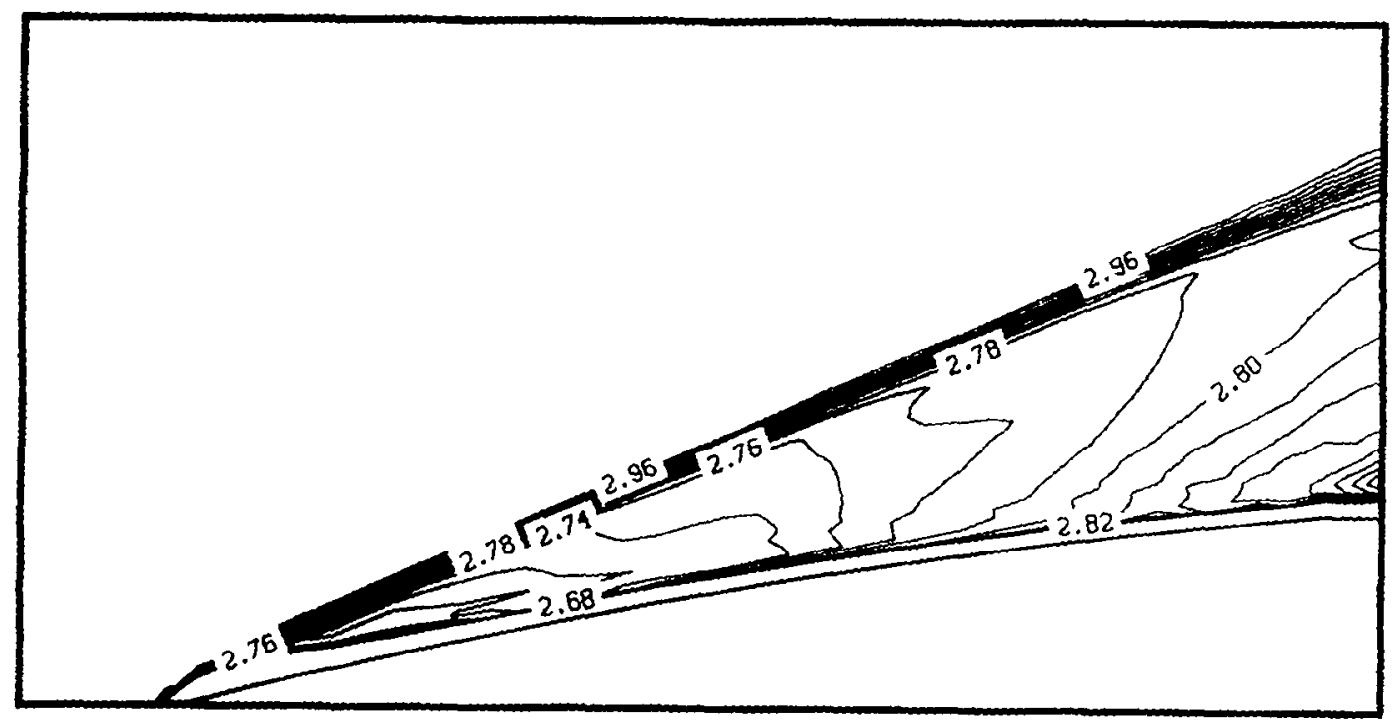

Fig. 7. Nose shock position shown by Mach number, $M_{x}=3.0$.

General features of the flowfield must be examined in order to gain confidence in the solution. Namely, there should be an attached oblique shock wave at the nose, as well as a well-defined recirculation region at the base. Figure 7 shows Mach number contours in the vicinity of the forebody. The shock wave is apparent in the region where the contours coalesce; shock waves decrease Mach number and increase both pressure and density discontinuously.

Pressure ratio profiles across the nose shock wave are presented in Fig. 8 . The profiles are shown at four locations along the body length, $Z / D=0.403,0.823,1.257$, and 1.692 . The profiles show a large gradient in pressure as the freestream flow encounters the shock and is compressed to nearly double the freestream value. The shock structure is maintained along the forebody length, with the shock strength decreasing slightly from $Z / D=0.402$ to $Z / D=1.692$. The viscous layer and shock layer regions are visible at axial locations aft of $Z / D=0.823$.

The next region of the flow which should be examined is the base. This region contains very complex flow dynamics due to the low pressure created at the base. This low pressure causes the

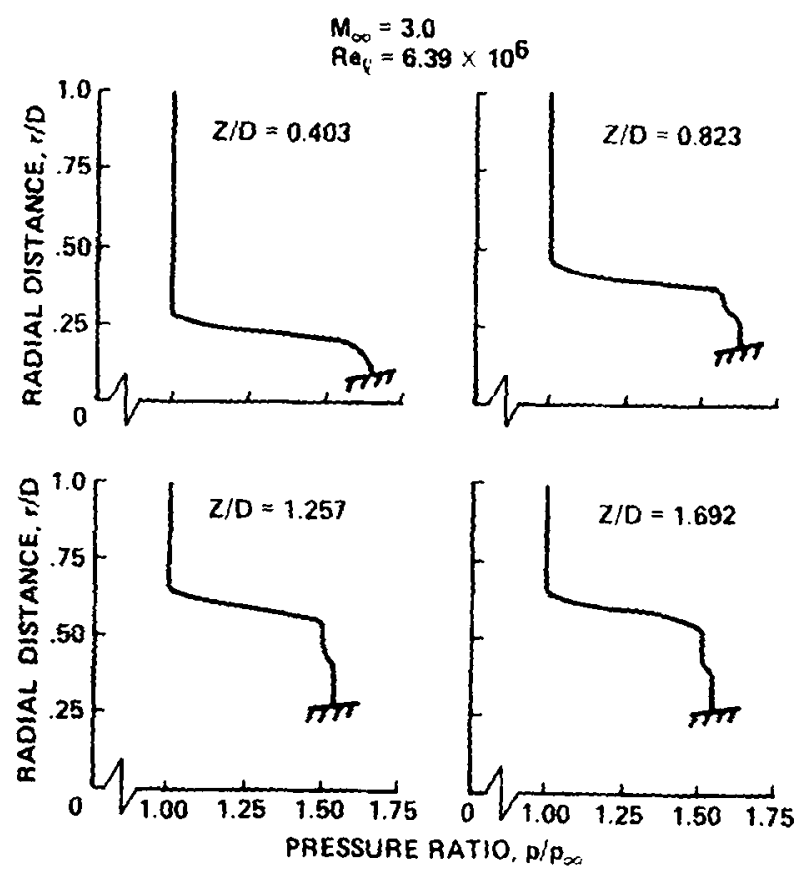

Fig. 8. Shock pressure gradients, $M_{x}=3.0$. 


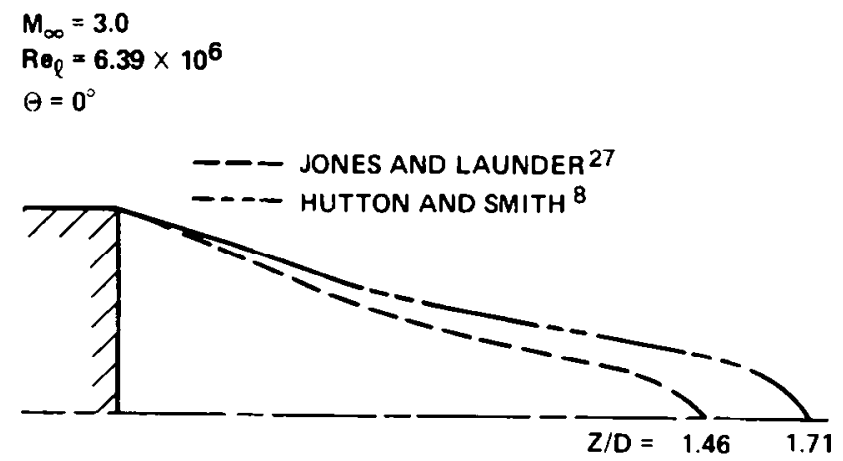

Fig. 9. Base recirculation region separating streamline, $M_{\varkappa}=3.0, \Theta=0$.

flow which is coming over the top of the base to recirculate and expand, accelerating the fluid which flows over the top of the recirculation region. The separating streamline of the recirculation region is shown in Fig. 9. The Jones and Launder model [27] predicts the flow reattachment to the centerline to be 1.46 diameters downstream of the base. However, Pope and Whitelaw [12] found that the original Jones and Launder model overpredicts the spreading rate of the turbulent shear layer, and therefore underpredicts the distance to the stagnation point of the dividing streamline. The Hutton and Smith model [8] yields an increased reattachment length of 1.71 body diameters. The predicted value of the length of the recirculation region is in qualitative agreement with numerical predictions at supersonic Mach numbers and similar Reynolds numbers by Sahu et al. $[14,15]$. Based on Pope and Whitelaw's findings concerning the overprediction of the turbulent shear layer spreading rate, the Hutton and Smith model was used for the remaining predictions.

Figure 10 shows velocity vectors drawn in the base region (the vector lengths are proportional to the velocity at that grid point). A companion visualization of the flow is shown by Mach number contours (Fig. 11). These contours show that the base region has an area of very low fluid velocity adjacent to the base. Also, the expansion of the flow around the corner can be seen to increase the speed of the flow above the recirculation region to values above freestream levels. The low pressure region extends well away from the base, then slowly recovers to near freestream levels as the higher velocity fluid feeds down over the recirculation region.

Surface pressure measurements have been made on the geometry of interest at Mach 3.0 [51]. Figure 12 shows the comparison of surface pressures at various axial locations along the body. The comparison between the measured data and the numerical prediction is very good, especially the prediction of the expansion which occurs in the vicinity of the shoulder of the nose, which is located at $Z=3.0$ diameters. The present numerical predictions are compared with a previous inviscid prediction by Reklis and Sturek [51]. While the overall accuracy of the two predictions is similar, the Navier-Stoke:s prediction yields better results than the inviscid predictions in the vicinity of body surface discontinuities. This is to be expected as the Navier-Stokes prediction includes the

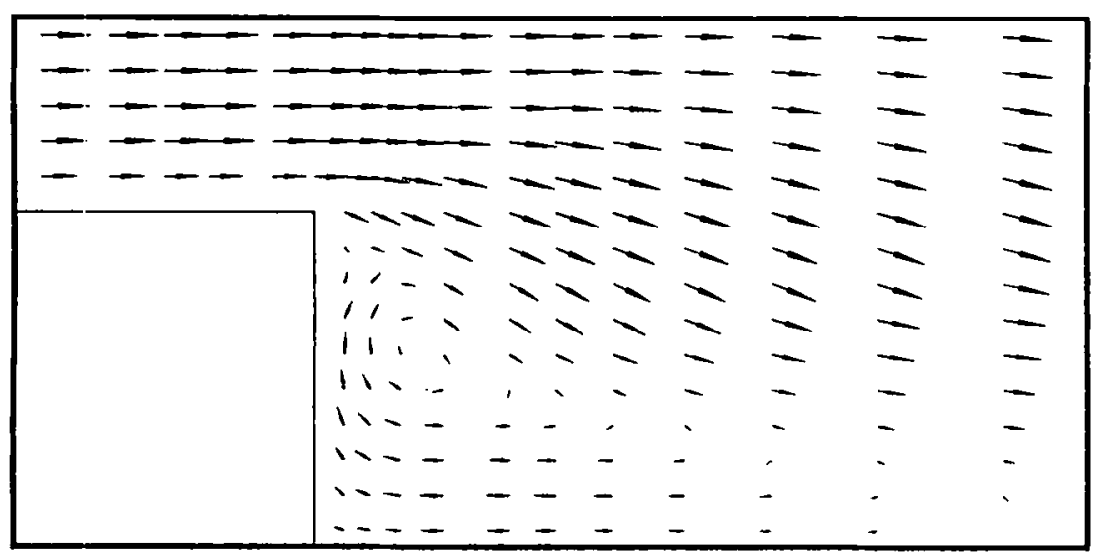

Fig. 10. Velocity vectors in base region, $M_{\chi}=3.0, \Theta=0$ 


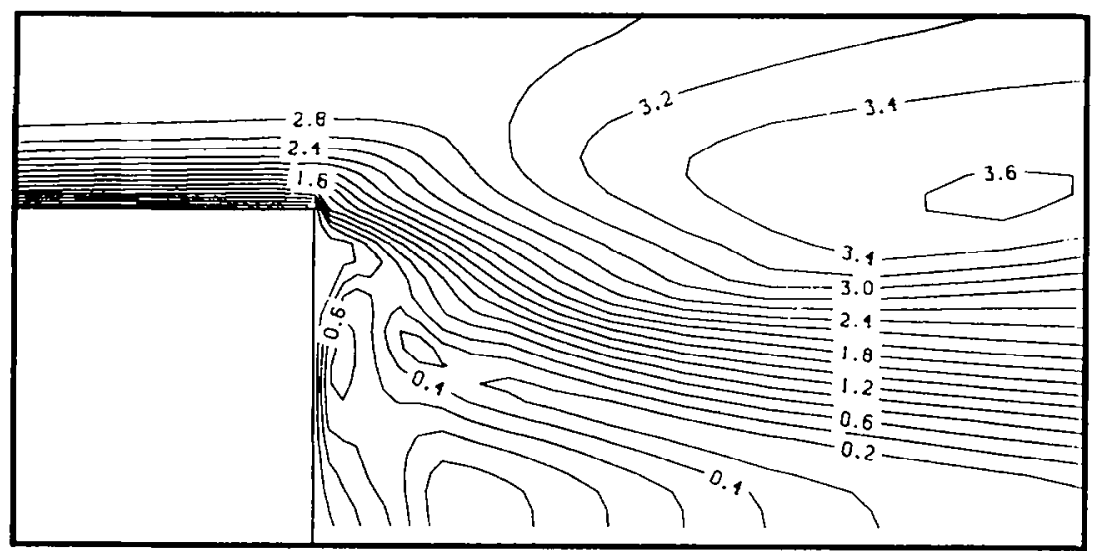

Fig. 11. Mach contours in base region, $M_{\alpha}=3.0, \Theta=0^{\circ}$.

interaction between the viscous layer and the flow expansion. These results are also in agreement with comparisons between a Parabolized Navier-Stokes prediction [52] and the inviscid results.

Unfortunately, the wind tunnel test did not include the measurement of base pressure; the predicted pressure variation across the base is shown in Fig. 13. As can be seen, the base pressure is a maximum near the centerline, where the recirculating flow stagnates at the base. As the flow turns upward along the base, lower pressures are exerted over the upper regions of the base. The average predicted base pressure along the base is $p / p_{\infty}=0.336$. Sedney [53] presents measured base pressure data from several sources for Mach numbers ranging from 1.5 to 5.8. At Mach 3.0 the empirical curve-fit yields a base pressure value of $p / p_{x}=0.350$, which compares well with the present prediction. The predicted value also compares well with the value given by simple supersonic theory for the pressure coefficient of base flow [54]

$$
C_{\mathrm{p}}=-\frac{1}{M_{\infty}^{2}}
$$

Equation (19) yields a value of $p / p_{\infty}=0.300$. This theory is mainly valid at higher Mach numbers, but gives a valuable reference point for determining the accuracy of the numerical prediction.

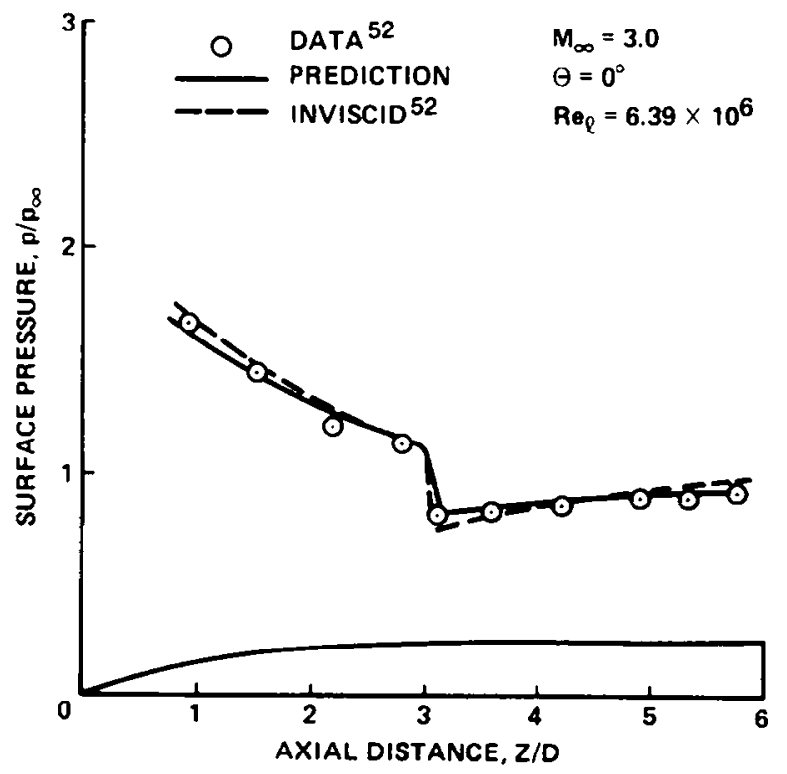

Fig. 12. Surface pressure comparison, $M_{\alpha}=3.0, \theta=0^{\circ}$. 


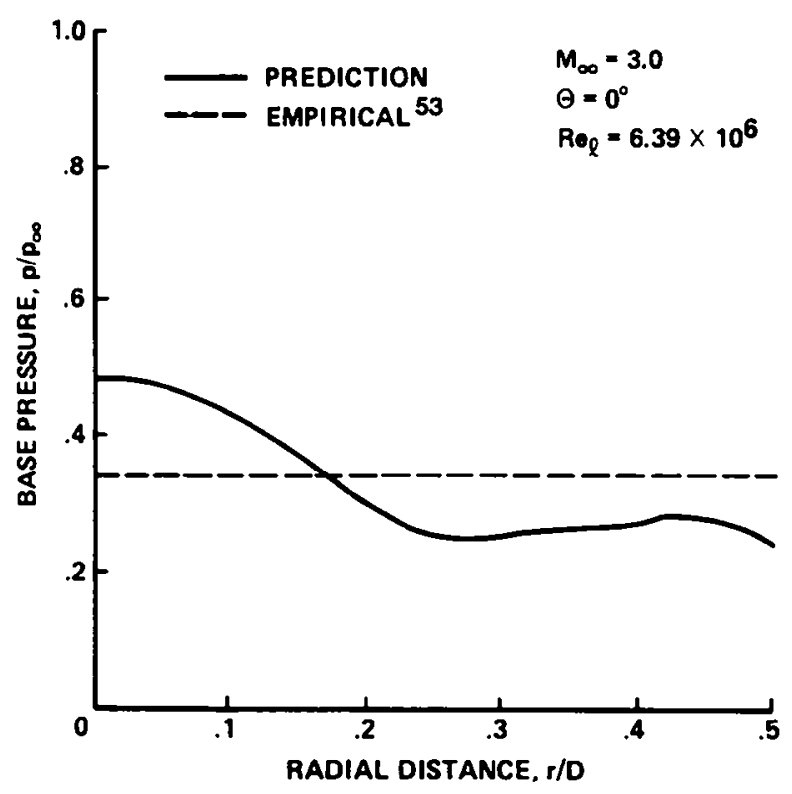

Fig. 13. Pressure variation over base, $M_{\infty}=3.0, \theta=0^{\circ}$.

Mach and temperature profiles within the viscous layer are presented in Figs 14 and 15. The profiles are presented for three axial locations, $Z / D=3.33,4.44$, and 5.56 diameters. The profiles show that the turbulence model produces reasonable results in the viscous layer. Since the main results required of the code are the gross forces acting on the body, it appears that the turbulence model is doing an adequate job in predicting viscous layer quantities.

The numerical results for the $7^{\circ}$ boattail case are now presented. The results for the shock at the nose are largely unchanged, as would be expected for a supersonic flow. However, the flowfield characteristics over the body and in the base region are quite different. The separating streamline of the recirculation region (Fig. 16) is smaller than that for the no boattail case (Fig. 9). In fact the recirculation region as predicted by the Jones and Launder model only extends 1.27 body diameters downstream from the base, a $13 \%$ reduction in the length of the recirculation region when compared with the case without a boattail. This reduction in the recirculation region is a direct result of the boattail; flow is being fed down into the base region at a $7^{\circ}$ angle, and is collapsing over the low pressure area in a smaller distance.

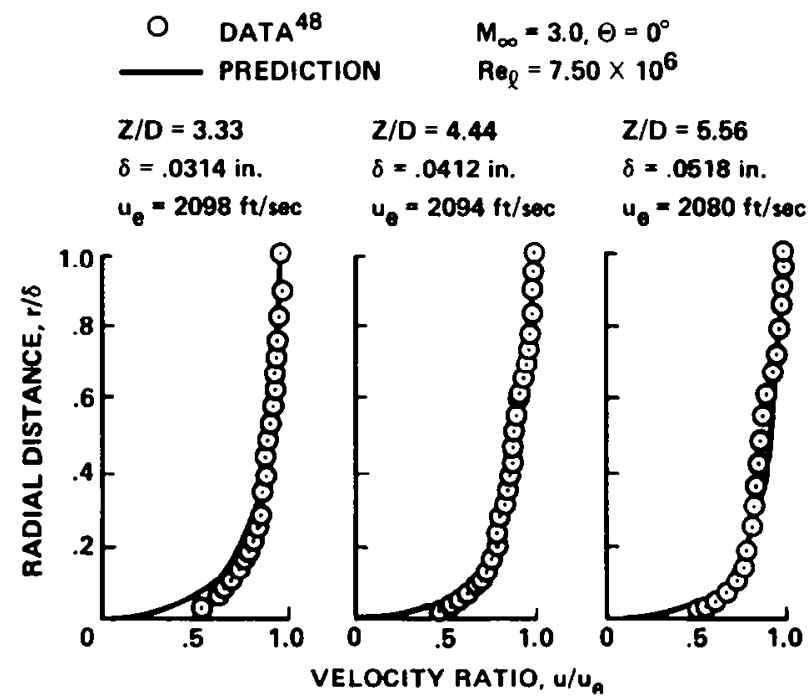

Fig. 14. Viscous layer velocity profiles, $M_{\alpha}=3.0, \theta=0^{\circ}$. 


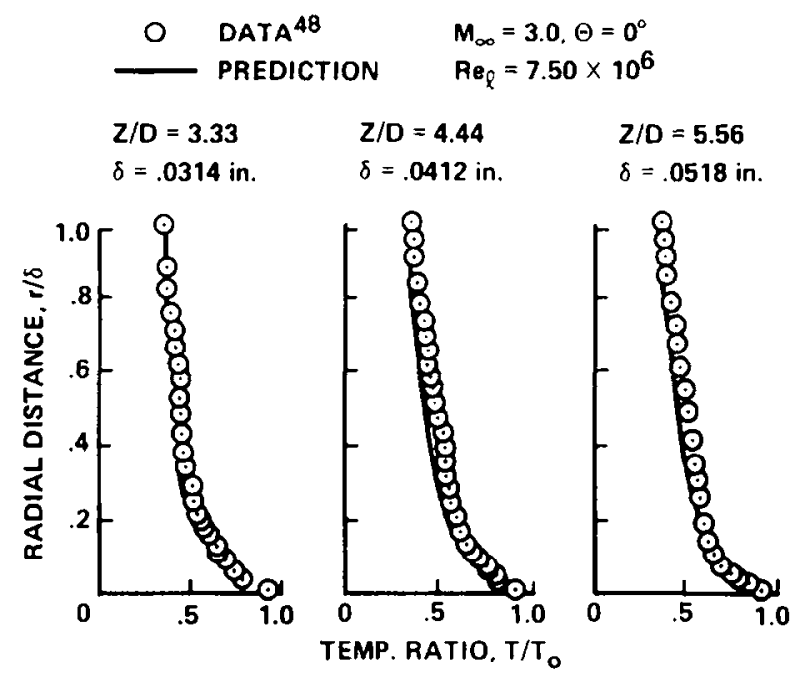

Fig. 15. Viscous layer temperature profiles, $M_{x}=3.0, \Theta=0^{r}$.

Figure 17 shows the velocity contours in the base region for the $7^{\circ}$ boattail; Fig. 18 presents Mach contours. Again, although the base region is qualitatively similar to the no boattail case, the recirculation region is noticeably smaller, with higher base pressures. Although this case shows an increased base pressure, overall drag is not necessarily reduced. The increase in base pressure occurs in conjunction with a reduced base area and an additional drag induced by the pressure acting along the boattail surface (Fig. 19). Also, the flow is more likely to separate along the boattail surface as the boattail angle is increased, which would greatly increase the body drag. Therefore, for boattail angles much higher than $10^{\circ}$, it is highly unlikely that the boattail will be beneficial.

The comparison of surface pressures and measured data for the $7^{\circ}$ boattail case are presented in Fig. 20. The prediction compares very well with the data, especially the magnitude and location of the flow expansion which occurs at the boattail juncture. The Navier-Stokes predictions again are comparable with the inviscid predictions. The base pressure variation for this case is presented in Fig. 21, and shows a similar variation across the base as the no boattail case. However, the pressure level is higher, with an average value of $p / p_{r_{i}}=0.404$. This is a result of the smaller recirculation region for the boattail case.

\section{DRAG OPTIMIZATION}

Now that reasonable flow solutions have been computed for the case of an axisymmetric body with a boattail afterbody, the optimization routine may be implemented in order to determine the boattail angle which gives minimum drag. A consideration when completing this optimization is to reduce the overall computer time; if the optimization routine were allowed to compute 5 to 10 configurations to full convergence starting from freestream initial conditions, the computer time would be quite high.

$$
\begin{aligned}
& M_{\infty}=3.0 \\
& R e_{\ell}=6.39 \times 10^{6} \\
& \Theta=7^{\circ}
\end{aligned}
$$

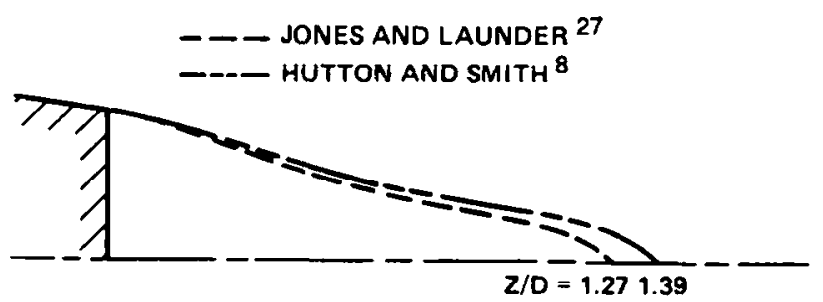

Fig. 16. Base recirculation region separating streamline, $M_{x}=3.0 . \Theta=7$. 


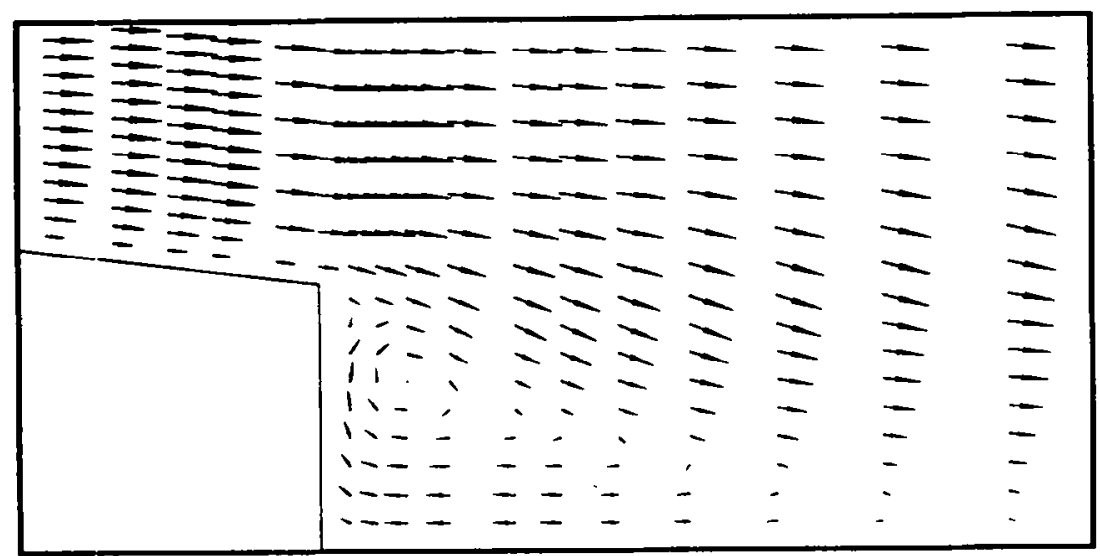

Fig. 17. Velocity vectors in base region, $M_{x}=3.0, \theta=7^{\circ}$

A solution to the problem of overall computational time during optimization is to allow the code to utilize the previously calculated flowfield information as initial conditions for the next case. The current code initializes with freestream conditions prescribed at all grid points (with the exception of the wall boundaries). The method must then form shocks, expansion fans, boundary layers, and the recirculating zone through hundreds of time steps. If, however, the initial conditions for any one case were the final solution from a geometrically similar, previously calculated case, the computation time for the second condition would be significantly reduced.

The Golden Section optimization method was allowed to choose the boattail angles for which it required objective function information (drag). The algorithm searched through a pattern of boattail angles as shown in Fig. 22. Note the intelligent search path, which utilizes previously obtained information. The algorithm obtained the minimum value of drag coefficient $\left(C_{\mathrm{D}}=0.306\right)$ at a boattail angle of $7.9^{\circ}$ in nine iterations within $1 \%$ accuracy.

In order to verify the initial assumption that the boattail length was inversely proportional to the drag of the body, an additional prediction was made with a longer boattail. The boattail length for the previous predictions of 1.0 body diameter resulted in an optimized body base radius corresponding to a $7.9^{\circ}$ boattail angle. This base radius was held constant and the boattail length was increased to 1.5 body diameters. The resulting drag coefficient was predicted to be $C_{\mathrm{D}}=0.281$, an eight percent reduction in drag when compared with the optimum drag coefficient for the 1.0 body diameter boattail. This prediction gives confidence in the original assumption, and re-enforces the decision to use the boattail angle as the only design variable.

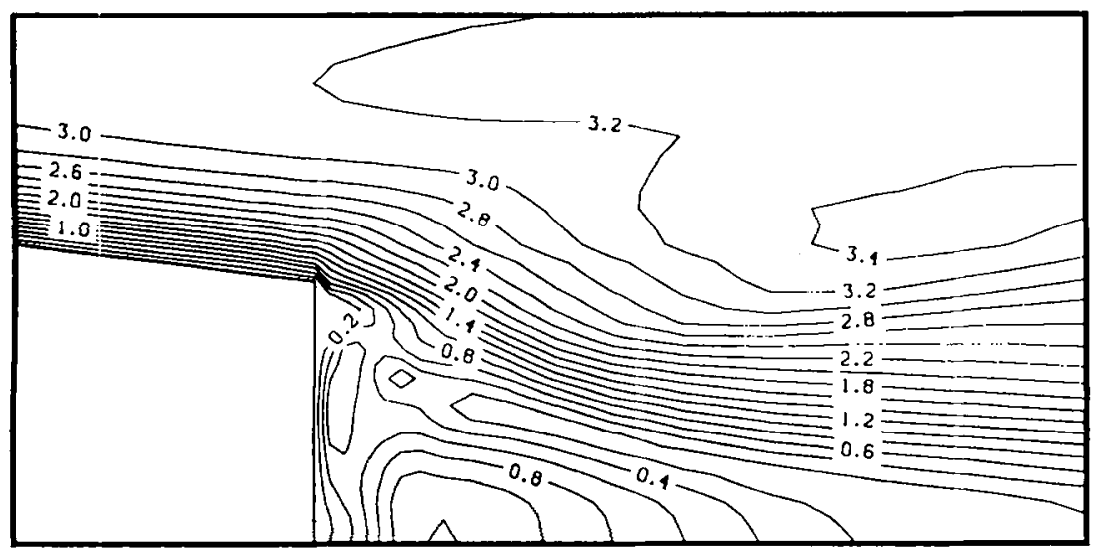

Fig. 18. Mach contours in base region, $M_{\star}=3.0, \Theta=7^{\circ}$. 


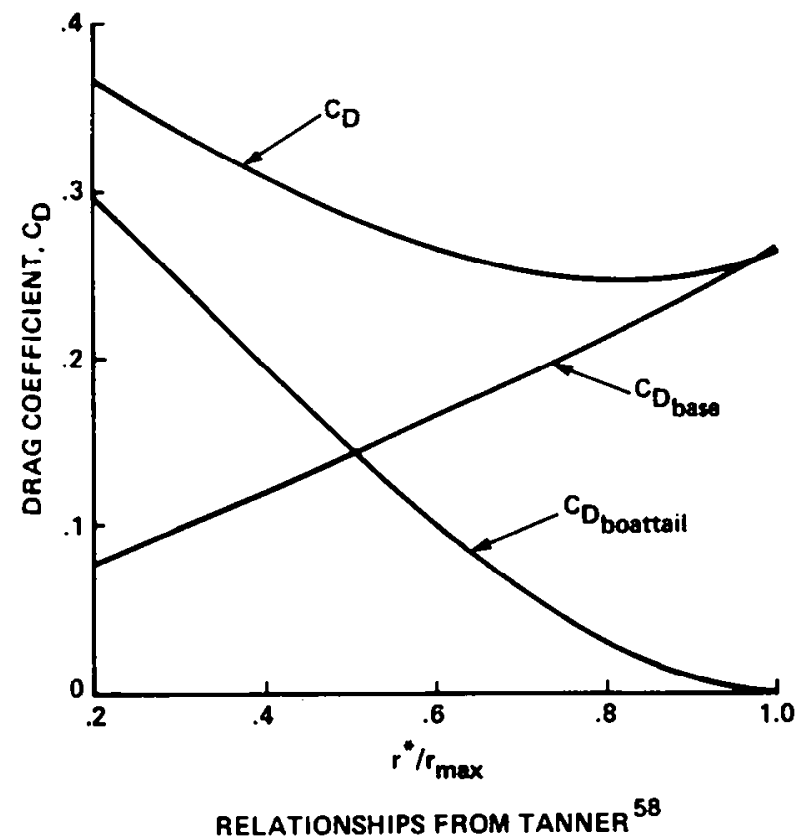

Fig. 19. Contributing factors to boattail drag.

\section{CONCLUSIONS}

The MacCormack unsplit explicit algorithm applied to the mass-averaged Navier-Stokes equations solved in conjunction with the Jones and Launder $k-t$ turbulence model has been shown to accurately predict the time-independent flowfield about axisymmetric body geometries at supersonic speeds. The numerical predictions were performed for a complete axisymmetric body, including a secant-ogive forebody, cylindrical afterbody, and conical boattail. The Golden Section search method was used to optimize the flowfield in order to predict the boattail angle for minimum overall drag (pressure drag, skin friction drag, and base drag). The optimization resulted in the prediction of a boattail angle for minimum drag of $7.9^{\circ}$, which compares favorably with available data for similar geometries.

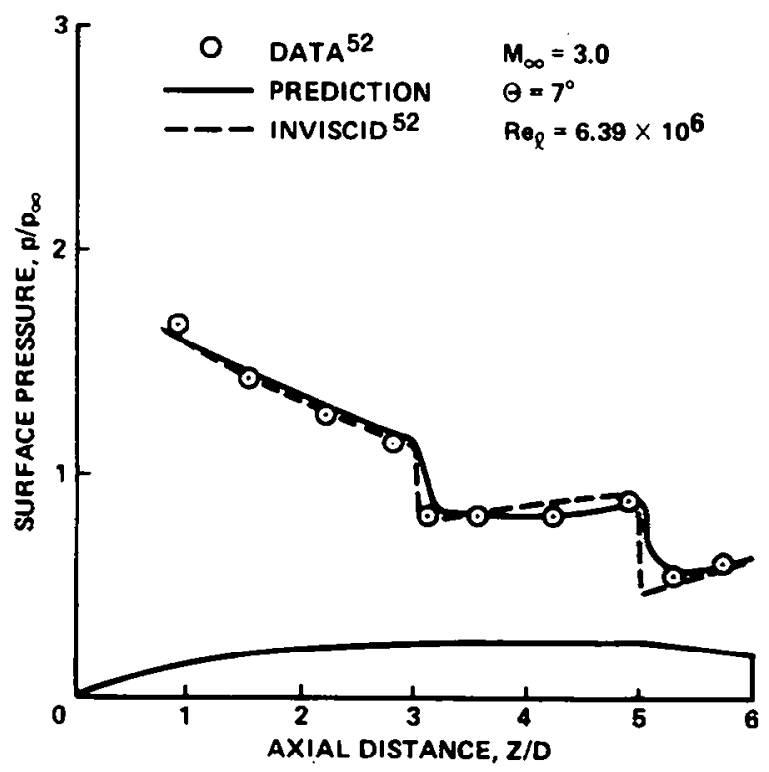

Fig. 20. Surface pressure comparison, $M_{x}=3.0, \theta=7^{\circ}$ 


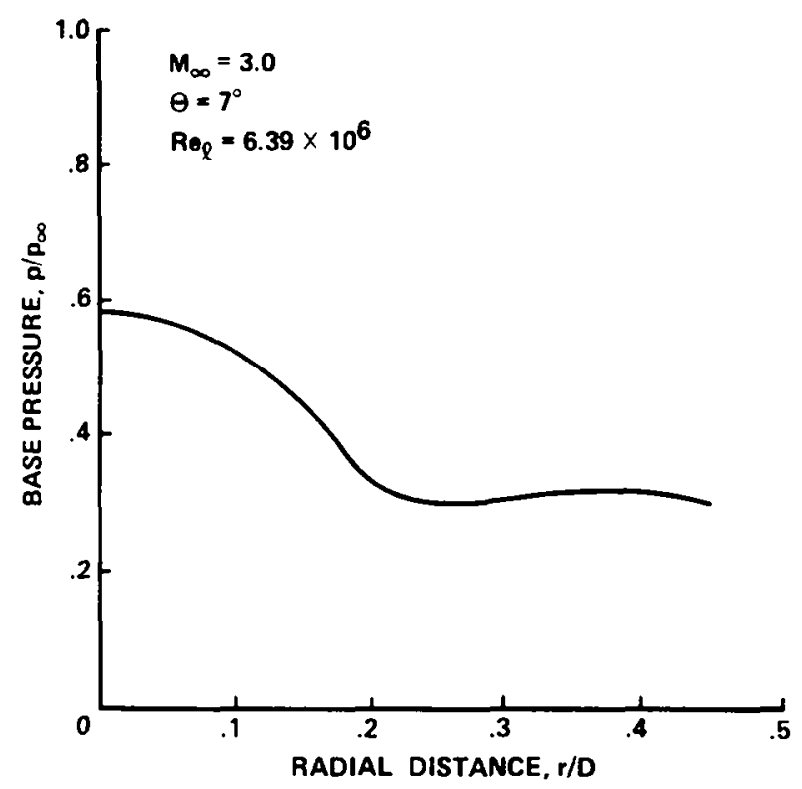

Fig. 21. Pressure variation over base, $M_{\infty}=3.0, \theta=7^{\circ}$.

The prediction of surface pressure compares well with available experimental results and inviscid predictions. The numerical prediction of surface pressure was an improvement over the inviscid results, especially in regions of body surface discontinuities (forebody cylinder and cylinderboattail junction). Comparisons of viscous layer profiles with available experimental data show that the $k \rightarrow$ turbulence model adequately describes the viscous features of the flow. Also, the qualitative features of the flow are well predicted (shock waves, expansion fans, and recirculation region).

The lack of experimental data containing flowfield information (such as viscous layer profiles, turbulence quantities, and flow visualization of shocks and expansion fans) for supersonic geometries is a great hindrance to validating a numerical code. Nietubicz [55] has found that there are virtually no supersonic experiments where flowfield quantities have been measured in the base region. An increased effort needs to be made to return to the wind tunnels and take an in-depth look at the fluid dynamic processes which occur in the flow around bodies at supersonic speeds.

Numerically, there are several areas where the solution of the Navier-Stokes equations could be improved. The current work utilizes an inviscid "characteristic" formulation for the upper inflow/outflow boundary; an improvement to this boundary condition which would overcome the limitation of using a finite computational domain has been suggested by Jafroudi and Yang [56]. They recommended obtaining the asymptotic solution for the compressible, turbulent Navier-Stokes equations at large distances from the finite body. The resulting equations could then

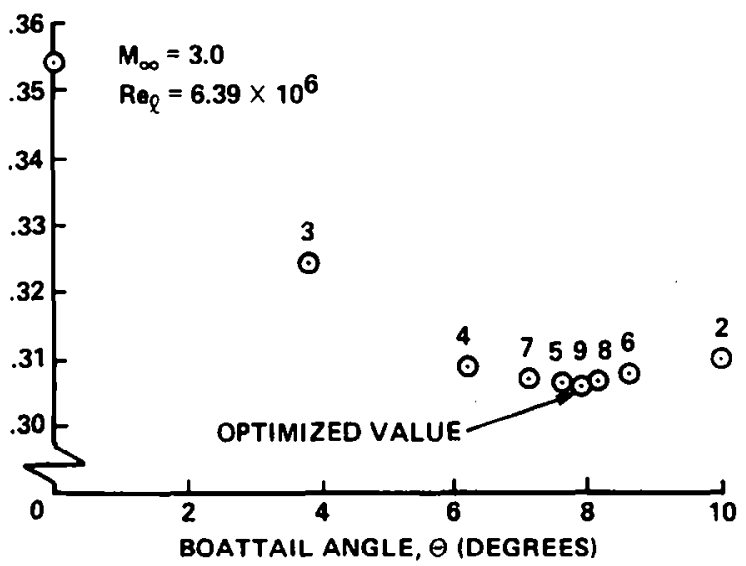

Fig. 22. Optimization search path. 
serve as the farfield boundary condition, and would overcome the problem of computing the unbounded flow over a finite body using a bounded computational region.

The $k \rightarrow$ turbulence model is known to overpredict the spreading rate of turbulent shear layers, and therefore underpredict the length of the base recirculation region. On [57] has developed a model for the pressure-dilatation correlation applicable to high Mach number free turbulent shear layers which would reduce the spreading rate and improve the prediction of the length of the recirculation region. Use of the additional modeled term could improve the prediction of base pressure, and therefore more accurately predict the drag of the axisymmetric body.

These computations show that the use of Navier-Stokes computations for preliminary configuration design is at hand. The use of optimization concepts can be applied to viscous flow calculations in an intelligent manner which yields reasonable results in relatively short computational times. This brings the advantages of optimization to the level of the practicing engineer for making informed preliminary design configuration choices.

Acknowledgement - -This research was supported in part by the Hughes Aircraft Company and its Advanced Education Program.

\section{REFERENCES}

1. S. N. B. Murthy and J. R. Osborn, Base flow phenomena with and without injection: experimental results, theories, and bibliography. In Aerodynamics of Base Combustion (Edited by S. N. B. Murthy), Vol. 40 of Progress in Astronautics and Aeronautics, 7-210. American Institute of Aeronautics and Astronautics, New York (1976).

2. G. S. Deiwert, Numerical simulation of three-dimensional boattail afterbody flowfields. $A$ IAA J. 19, 582-588 (1981).

3. G. S. Deiwert, A computational investigation of supersonic axisymmetric flow over boattails containing a centered propulsive jet. $A I A A J$. 22, 1358-1365 (1984).

4. G. S. Deiwert and $H$. Rothmund, Three-dimensional flow over a conical afterbody containing a centered propulsive jet: a numerical simulation. AIAA Paper 83-1709 (1983).

5. A. D. Gosman. E. E. Khalil and J. H. Whitelaw, The calculation of two-dimensional turbulent recirculating flows. In Turbulent Shear Flows $I$ (Edited by F. Durst et al.), pp. 237-255. Springer, Berlin (1979).

6. C. Hah and B. Lakshminarayana, The prediction of two- and three-dimensional asymmetrie turbulent wakes-a comparison of the performance of three turbulence models for the effects of streamline curvature and rotation. AIAA Paper 79-1561 (1979).

7. T. L. Holst, Numerical solution of axisymmetric boattail fields with plume simulators. AIAA Paper 77-224 (1977).

8. A. G. Hutton and R. M. Smith, A study of two-equation turbulence models for axi-symmetric recirculating flow. Proc. of the Third Int. Conf. on Numerical Methods in Laminar and Turbulent Flow, 811 August 1983. 233-247. Pineridge Press, Swansea, Wales (1983).

9. N. N. Mansour, J. Kim and P. Moin. Computation of turbulent flows over a backward-facing step. NASA Technical Memorandum 85851 (1983).

10. A. G. Mikhail, W. L. Hankey and J. S. Shang, Computation of a supersonic flow past an axisymmetric nozzle boattail with jet exhaust. AlAA J. 18, 869.875 (1980).

11. Y. H. Oh and J. E. Harris, Numerical solution of three-dimensional free turbulent shear flows, Proc. of a Symp. on Turbulent Shear Flows, 18-20 April 1977, Penn State, University Park (1977).

12. S. B. Pope and J. H. Whitelaw, The calculation of near-wake flows. J. Fluid Mech. 73, 932 (1976).

13. C. M. Rhie and W. L. Chow, Numerical study of the turbulent flow past an airfoil with trailing edge separation. $A I A A$ J. 21, 1525-1532 (1983).

14. J. Sahu, C. J. Nietubicz and J. L. Steger, Navier -Stokes computations of projectile base flow with and without base injection. AIAA J. 23, 13481355 (1985)

15. J. Sahu. C. J. Nietubicz and J. L. Steger, Numerical computation of base flow for a projectile at transonic speeds. AIAA Paper 82-1358 (1982).

16. W. B. Sturek, C. J. Nietubicz, J. Sahu and P. Weinacht, Application of computational fluid dynamics to the aerodynamics of army projectiles. $J$. Spacecraft Rockets 31, 186-199 (1994).

17. S. P. Vanka, Computation of turbulent recirculating flows with fully coupled solution of momentum and continuity equations. Argonne National Lab. Report ANL-83-74 (1983).

18. B. C. Weinberg. H. McDonald and S. J. Shamroth. Navier-Stokes computations of aft end flow fields. U.S. Army Research Office Report ARO - I5905 (1982).

19. R. S. Rogallo and P. Moin, Numerical simulation of turbulent flows. In Annual Review of Fluid Mechanics 16 (Edited by M. Van Dyke et al.), pp. 99-137. Annual Reviews, Palo Alto (1984).

20. D. L. Turcotte, Fractals in fluid mechanics. In Annual Review' of Fluid Mechanics 20 (Edited by J. L. Lumley et al.), pp. 5. 16. Annual Reviews, Palo Alto (1988).

21. T. Hesselberg. Die Gesetze der ausgeglichene Atmospharischen Bewegungen. Beit. Phys. Freien Atmos. 12, 141-160 (1926).

22. A. Favre. Equations des gaz turbulents compressibles. J. Méc. 4, 361390 (1965).

23. A. Favre, Statistical equations of turbulent gases. In Problems of Hydrodynamics and Continuum Mechanics 231 - 266. Society for Industrial and Applied Mathematics, Philadelphia (1969).

24. P. Bradshaw. Effects of streamline curvature on turbulent flow. AGARD Report AG-169 (August 1973).

25. H. P. A. H. Irwin and P. A. Smithe, Prediction of the effect of streamline curvature on turbulence. Phys. Fluids 18, $624630(1975)$.

26. B. E. Launder and D. B. Spalding, Lectures in Mathematical Models of Turbulence. Academic Press, London (1972). 
27. W. P. Jones and B. E. Launder, The calculation of low-Reynolds-number phenomena with a two-equation model of turbulence. Int. J. Heat Mass Transfer 16, 1119-1130 (1973).

28. M. W. Rubesin, Numerical turbulence modeling. AGARD Report LS-86 (1977).

29. M. V. Morkovin, Effects of compressibility on turbulent-flows. In The Mechanics of Turbulence (Edited by A. Favre) 367-380. Gordon \& Breach, New York (1964).

30. M. W. Rubesin, Compressibility effects in turbulence modeling. Proc. of the 1980-81 AFOSR-HTTM-Stanford Conf. on Complex Turbulent Flows, 14-18 Sept. 1981 Stanford University Department of Mechanical Engineering, 713-723 (1982).

31. A. Liakopoulos, Computation of high speed turbulent boundary-layer flows using the $k-t$ turbulence model. Int. $J$. Numer. Methods Fluids 5, 81-97 (1985).

32. W. P. Jones and B. E. Launder, The prediction of laminarization with a two-equation model of turbulence. Int. J. Heat Mass Transfer 15, 301-314 (1972).

33. J. Boussinesq, Theorie de l'ecoulement tourbillant. Mem. Presentes Divers Savants Sci. Math. Phys. 23, 46-51 (1877).

34. R. M. Cummings, Compressible, turbulent flow computation and drag optimization for axisymmetric afterbodies. Ph.D. Dissertation, Univ. of Southern California (December 1988).

35. M. W. Rubesin and W. C. Rose, The turbulent mean-flow, Reynolds-stress, and heat-flux equations in mass-averaged dependent variables. NASA Technical Memorandum X-62248 (1973).

36. R. W. MacCormack. The effect of viscosity in hypervelocity impact cratering. AIAA Paper 69-354 (1969).

37. D. A. Anderson, I. C. Tannehill and R. H. Pletcher, Computational Fluid Mechanics and Heat Transfer, pp. $482-485$. McGraw-Hill, New York (1984).

38. J. C. Tannehill, T. L. Holst and J. V. Rakich. Numerical computation of two-dimensional viscous blunt body flows with an impinging shock. AIAA Paper 75-154 (1975).

39. P. J. Roache, Computational Fluid Dynamics, p. 302. Hermosa Publishers, Albuquerque (1982).

40. Y. H. Oh, An analytical transformation technique for generating uniformly spaced computational mesh. Numerical Grid Generation Techniques, NASA Conference Publication 2166 (1980).

41. Y. H. Oh, An anaiytical transformation technique for generating uniformly spaced computational mesh. Old Dominion University Research Foundation (October 1978).

42. R. Peyret and T. D. Taylor, Computational Methods for Fluid Flow, 2nd Ed. Springer, New York (1990).

43. G. A. Bekey, System identification-an introduction and a survey. Simulation, 151-166 (October 1970).

44. H. Ashley, On making things best-aeronautical uses of optimization. AIAA Paper 81-1738 (1981).

45. R. W. Hamming, Optimization. In Numerical Methods for Scientists and Engineers, 2nd Ed., pp. 657-676. McGraw-Hill, New York (1973).

46. B. Kneubuehl, Optimization of boattails for small arms bullets. Swiss Federal Department of Defence, Report PB85-143758 (1983).

47. R. Fletcher, Unconstrained Optimization. Wiley, Chichester (1980).

48. L. D. Kayser and W. B. Sturek, Experimental measurements in the turbulent boundary layer of a yawed, spinning ogive-cylinder boidy of revolution at Mach 3.0. U.S. Army Ballistic Research Laboratory Memorandum MR-2813 (March 1978).

49. L. D. Kayser, W. J. Yanta and W. B. Sturek, Measurement in the turbulent boundary layer of a yawed, spinning body of revolution at Mach 3.0 with a laser velocimeter and impact probe. U.S. Army Ballistic Research Laboratory Technical Report TR-2074 (May 1978).

50. L. D. Kayser and W. B. Sturek, Turbulent boundary layer measurements on the boattail section of a yawed, spinning projectile shape at Mach 3.0. U.S. Army Ballistic Research Laboratory Memorandum MR-2880 (November 1978).

51. R. P. Reklis and W. B. Sturek, Surface pressure measurements on slender bodies at angle of attack in supersonic flow. U.S. Army Ballistic Research Laboratory Memorandum MR-2876 (November 1978).

52. L. B. Schiff and W. B. Sturek, Numerical simulation of steady supersonic flow over an ogive cylinder boattail body, U.S. Army Ballisic Research Laboratory, Report 2363 (September 1981).

53. R. Sedney, Review of base drag. U.S. Army Ballistic Research Laboratory, Report 1337 (October 1966).

54. S. E. Hoerner, Base drag and thick trailing edges. J. Aeronaut. Sci. 17, 622 (1950).

55. C. J. Nietubicz, C'urrent CFD efforts in projectile aerodynamics. NASA CFD Validation Workshop (Edited by J. G. Marvin) Moffett Field, CA, (14-16 July 1987).

56. H. Jafroudi and H. T. Yang, Steady laminar forced convection from a circular cylinder. J. Comput. Phys. 65, 46-56 (1986).

57. Y. H. Oh, Analy:is of two-dimensional free turbulent mixing. AIAA Paper 74-594 (1974).

58. M. Tanner, Steacy base flows. Progr. Aerospace Sci. 21, $81-157$ (1984). 